\title{
PELATIHAN PENGEMBANGAN MEDIA PEMBELAJARAN BERBASIS ICT GURU SMP/MTS YANG TERGABUNG MUSYAWARAH GURU MATA PELAJARAN (MGMP) KOTA PANGKALPINANG
}

\author{
Ali Ibrahim ${ }^{1 *}$, Allsela Meiriza ${ }^{2)}$, Fathoni ${ }^{3)}$, Yadi Utama ${ }^{4)}$, Hadi Purnawan Satria ${ }^{5)}$, \\ M.Rudi Sanjaya' ${ }^{6}$, Beriadi Agung Nur Rezqe ${ }^{7)}$, \& Akbar Alzaini ${ }^{8}$ \\ 1,2,3,4,6,7,8) Program Studi Sistem Informasi, Fakultas Ilmu Komputer, Universitas Sriwijaya \\ ${ }^{1,5}$ Program Studi Teknik Informatika, Fakultas Ilmu Komputer, Universitas Sriwijaya \\ ${ }^{2)}$ Program Studi Peternakan, Fakultas Pertanian, Universitas Muhammadiyah Bengkulu \\ e-mail: aliibrahim@unsri.ac.id, allsela_meiriza@yahoo.co.id, fathoni@unsri.ac.id,yadi@unsri.ac.id, \\ m.rudi.sjy@gmail.com, beriadiberlix@gmail.com, akbaralzaini@gmail.com. \\ *Corresponding author: aliibrahim@unsri.ac.id
}

\begin{abstract}
ABSTRAK
Guru mata pelajaran dituntut untuk memiliki kemampuan professional yang sesuai dengan Standar Nasional Pendidikan, yaitu setiap guru harus memiliki kompetensi pedagogic, kepribadian, professional dan social. Pengembangan keempat kompetensi tersebut perlu terus dikembangkan, baik melalui pendidikan, pelatihan, maupun kerja kelompok atau organisasi profesi guru. Rendahnya hasil belajar siswa salah satunya disebabkan karena guru belum menggunakan media animasi dalam proses pembelajaran. Proses pembelajaran masih berlangsung secara konvensional, dimana aktivitas menulis lebih dominan dilakukan oleh guru dalam mengajar. Dengan pelatihan program Quipper School dapat meningkatkan keterampilan para guru dalam membuat media ajar berbasis multimedia. program Quipper School adalah platform sekolah digital tanpa biaya. Melalui platform ini, guru dapat mengirim dan mengelola materi pembelajaran, ujian, serta nilai siswa. Metode yang digunakan dalam pelatihan adalah dengan cara peragaran dan demontrasi program Quipper School. Dari hasil kuisiner setelah pelatihan $90 \%$ peserta berhasil dalam membuat media ajar.
\end{abstract}

Kata Kunci: Quipper School, MGMP, Multimedia

\section{A. PENDAHULUAN}

Musyawarah Guru Mata Pelajaran

(MGMP) Kota Pangkalpinang merupakan

wadah yang terorganisasi non struktural dari Dinas Pendidikan Kota

Pangkalpinang. Pendidikan Nasional bertujuan untuk mengembangkan potensi peserta didik agar menjadi manusia yang beriman dan bertaqwa kepada Tuhan Yang Maha Esa, berakhlak mulia, sehat dan berilmu, cakap dan kreatif, mandiri dan menjadi warga Negara yang demokratis dan bertanggungjawab. Salah satu faktor kunci untuk mengembangkan potensi peserta didik agar menjadi manusia yang beriman dan bertakwa kepada Tuhan Yang Maha Esa, sebagaimana diamanatkan dalam tujuan pendidikan nasional di atas, adalah terletak pada peran guru. 
MGMP pada sekolah sebagaimana guru mata pelajaran lainnya dituntut untuk memiliki kemampuan professional yang sesuai dengan Standar Nasional Pendidikan, yaitu setiap guru harus memiliki kompetensi pedagogic, kepribadian, professional dan social. Pengembangan keempat kompetensi tersebut perlu terus dikembangkan, baik melalui pendidikan, pelatihan, maupun kerja kelompok atau organisasi profesi guru. MGMP Kota Pangkalpinang secara umum belum sepenuhnya berjalan secara optimal. Meski demikian, terdapat beberapa MGMP yang telah memiliki beragam aktivitas, seperti pendidikan, pelatihan, dan peningkatan keinerja sebagai Guru. Proses belajar mengajar di sekolah-sekolah secara umum telah berjalan dengan baik, tetapi rata-rata hasil belajar siswa masih tergolong rendah. Menurut beberapa guru yang tergabung dalam MGMP, rendahnya hasil belajar siswa salah satunya disebabkan karena guru belum menggunakan media animasi dalam proses pembelajaran. Proses pembelajaran masih berlangsung secara konvensional, dimana aktivitas menulis lebih dominan dilakukan oleh guru dalam mengajar.

Alasan utama mengapa para guru belum menggunakan media animasi dalam pembelajaran antara lain karena para guru belum mengerti, belum mamahami bagaimana cara membuat media ajar berbasis animasi. Solusi dari permasalahn tersebut adalah dengan diselenggarakan suatu pelatihan khusus yaitu pengembangan pembuatan media ajar berbasis ICT. Sehingga para guru dapat membuat media ajar yang lebih interaktif dan dapat meningkatkan proses belajar di sekolah. Pada kegiatan pelatihan, diikuti oleh para guru yang mewakili sekolah SMP/MTs di sekitar Pangkalpinag. Jumlah khalayak yang ikut dalam pelatihan adalah 25 orang guru.

\section{B. METODE KEGIATAN}

Metode yang ditawarkan kepada khalayak sasaran adalah melalui Pelatihan Pengembangan Media Pembelajaran Berbasis ICT Guru SMP/MTs Yang Tergabung Musyawarah Guru Mata Pelajaran (MGMP) Kota Pangkalpinang dengan program Quipper School. Langkah-langkah rencana kegiatan adalah sebagai berikut:

1. Tim Pelaksanaan Pembuatan dokumentasi pelaksanaan pelatihan dengan membuat formulir bagi peserta, seperti formulir daftar hadir, dan formulir isian tanggapan terhadap pelatihan, dan lain-lainnya, sebagai bukti pendukung pelaksanaan pelatihan;

2. Tim Pelaksana menyiapkan bahan (modul) pelatihan yang disesuaikan dengan kondisi sosial dan pendidikan khalayak, dan menyiapkan peralatan 
pelatihan dan sarana demonstrasi Program Quipper School Dalam Proses Pembuatan Media Ajar Interaktif Berbasis animasi multimedia;

3. Demonstrasi Aplikasi oleh tutor dan tim pelaksana, dengan bimbingan Tim Pelaksana. Tim Pelaksana membina khalayak, dengan diskusi (tanya jawab), membimbing, mengawasi, dan mengevaluasi kegiatan. Tolak ukur kegiatan evaluasi ini meliputi: (a) Daya serap khalayak; (b) Pengumpulan data, informasi, gambar; (c) Penggunaan aplikasi dalam pembuatan media ajar interaktif berbasis animasi;

(d) Proses pengelolaan media ajar interaktif berbasis animasi; (e) Jumlah data, informasi, gambar dan kualitas media ajar interaktif berbasis animasi secara keseluruhan yang mampu dihasilkan.

4. Pelaksanaan Pelatihan Pengembangan Media Pembelajaran Berbasis ICT Guru SMP/MTs Yang Tergabung Musyawarah Guru Mata Pelajaran (MGMP) Kota Pangkalpinang dengan garis besar materi meliputi: (a) Pengenalan Program Quipper School; (b) Pencarian Bahan; (d) Mendaftar dan Membuat Akun Baru; (e) Membuat Kelas dan Membagikan Kode Kelas ke Siswa; (f) Mengirimkan Tugas ke Akun QLearn; (g) Memantau Proses Belajar Siswa; (h) Memantau Proses Belajar Siswa; (i) Mengundang
Guru Bergabung di Akun Sekolah (j) Menambahkan Bidang Studi Baru.

5. Metode pelaksanaan Pelatihan Pengembangan Media Pembelajaran Berbasis ICT Guru SMP/MTs Yang Tergabung Musyawarah Guru Mata Pelajaran (MGMP) Kota Pangkalpinang, adalah sebagai berikut :a) Memberikan penjelasan kepada guru-guru perihal pembuatan perangkat ajar dalam peningkatan kualitas proses pembelajaran. b) Memberikan pelatihan kepada guruguru untuk dapat menggunakan Program Quipper School. c) Memberikan peragaan kepada guruguru interaktif menggunakan Program Quipper School.

\section{HASIL DAN PEMBAHASAN}

Kegiatan pengabdian kepada masayrakat dilaksanakan di SMPN1 Pangkalpiang. Peserta pelatihan adalah perwakilan dari beberapa SMP/MTS yang ada di sekitar pangkalpinang. Berikut foto kegiatan tim pelaksana dan tutor, seperti terlihat pada gambar 1, 2 dan 3:

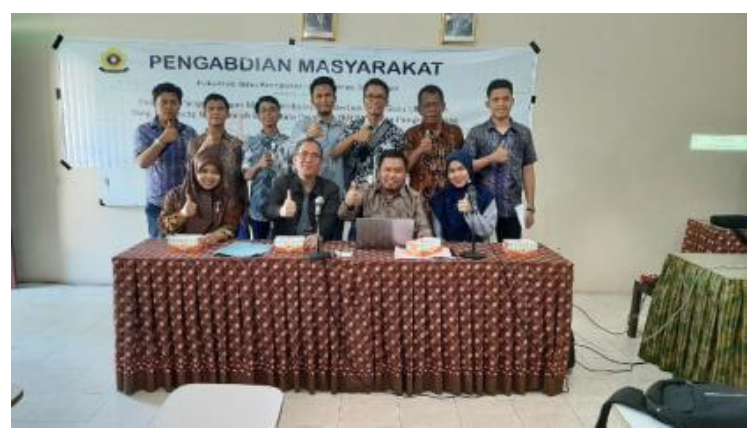

Gambar 1. Foto tim pelaksana dan tutor 


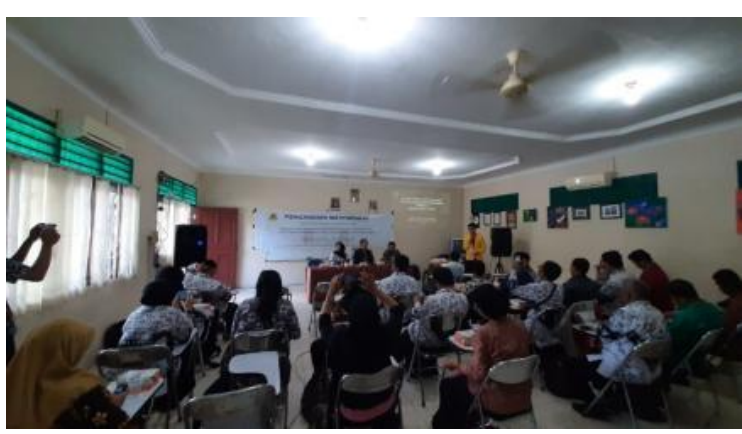

Gambar 2. Foto Pembukaan kegiatan oleh dinas pendidikan

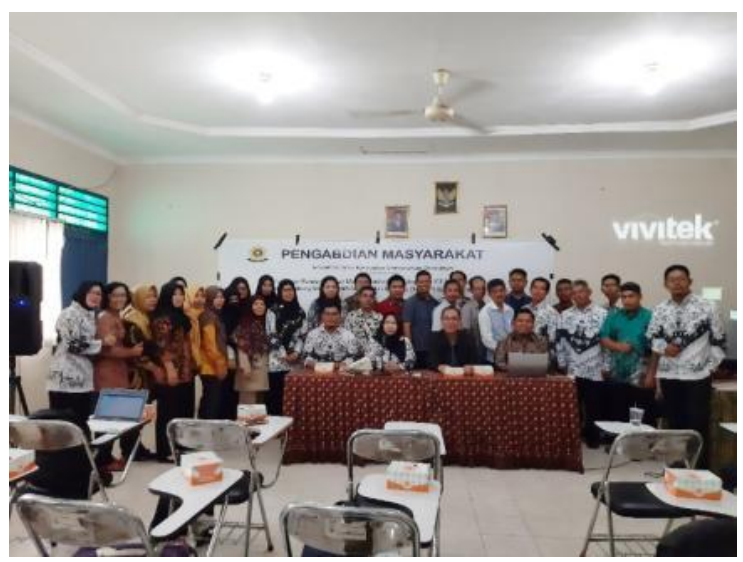

Gambar 3. Foto Bersama dengan peserta

Setelah kegiatan secara resmi di buka oleh perwakilan dinas Pendidikan pangkalpinang, selanjutnya kegiatan pertama dilanjutkan oleh pemaparan materi oleh narasumber Bapak Ali Ibrahim dari Fasilkom Unsri. Tema dari kegiatan ini adalah pentingnya peran ICT dalam mendukung proses belajar sehingga menjadi lebih interaktif. Dan bagaimana seorang guru harus mampu menyembangan media pembelajaran berbasis multimedia. Seperti terlihat pada gambar 4 dan 5 .

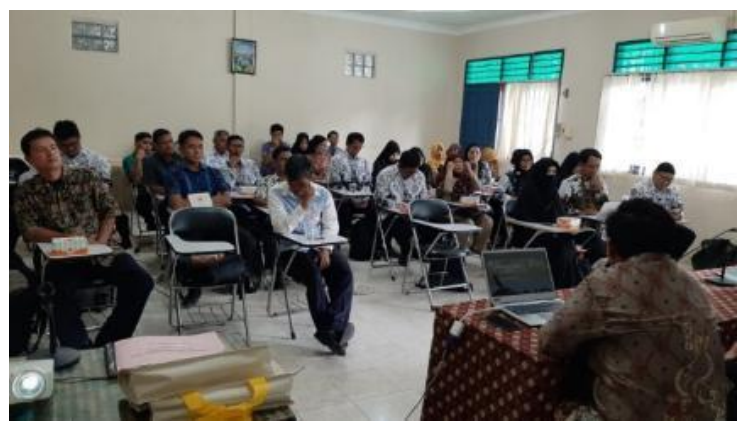

Gambar 4. Penyampaian materi

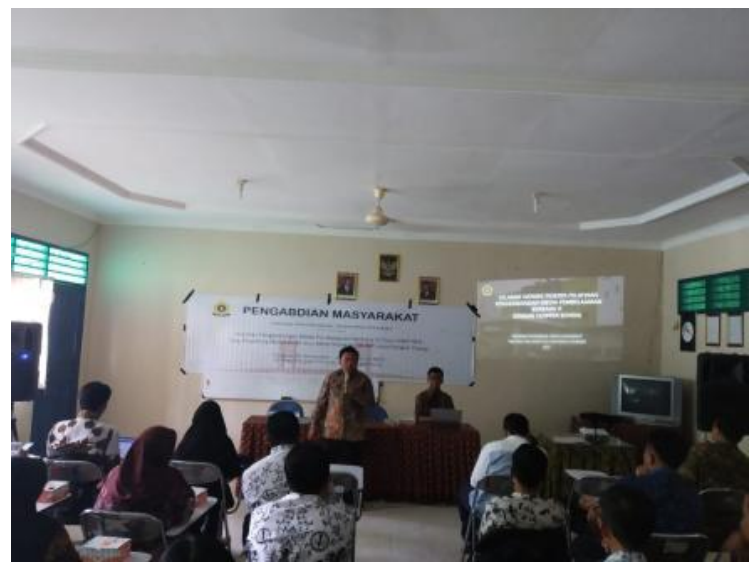

Gambar 5. Penyampaian materi

Kegiatan kedua Memberikan pelatihan kepada guru-guru untuk dapat menggunakan Program Quipper School. Quipper School adalah platform sekolah digital tanpa biaya. Melalui platform ini, guru dapat mengirim dan mengelola materi pembelajaran, ujian, serta nilai siswa. Siswa dapat mengerjakan pekerjaan rumah, tugas, dan ujian secara online dengan mudah. Berikut gambar tampilan Quipper School pada gambar 6.

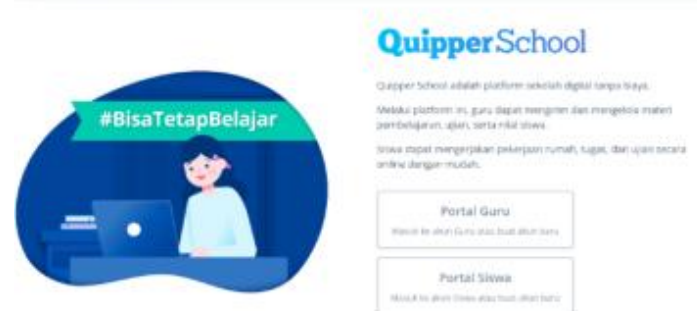


Gambar 6. tampilan Quipper School

Pada Quipper School ada 2 portal yaitu portal guru dan portal siswa. Kedua portal inilah yang akan di peragakan dan diikuti oleh semua khalayak dengan menggunakan laptop dan handphone. Seperti pada gambar 7 .

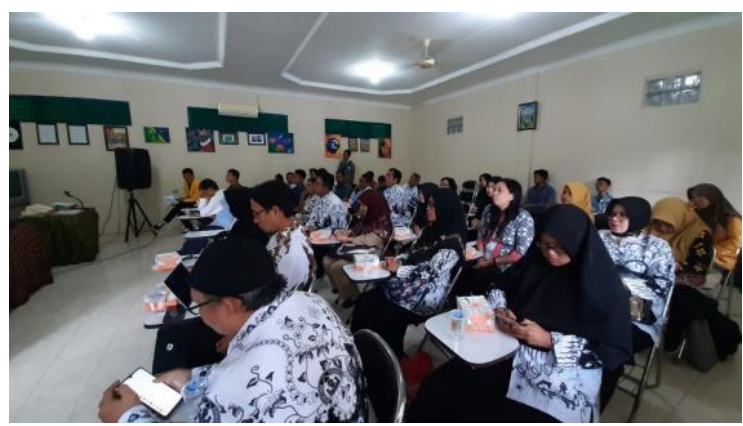

Gambar 7. Khalayak sedang mempraktikan Quipper School.

Kegiatan ketiga adalah memperagakan program Quiper Scholl oleh narasumber dan tim.

1. Membuat Kelas dan Membagikan Kode Kelas ke Siswa

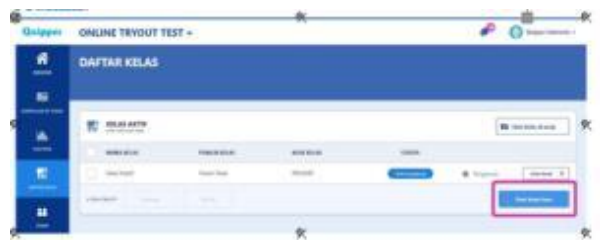

Gambar 8. Membuat kelas

2. Mengirimkan Tugas ke Akun QLearn

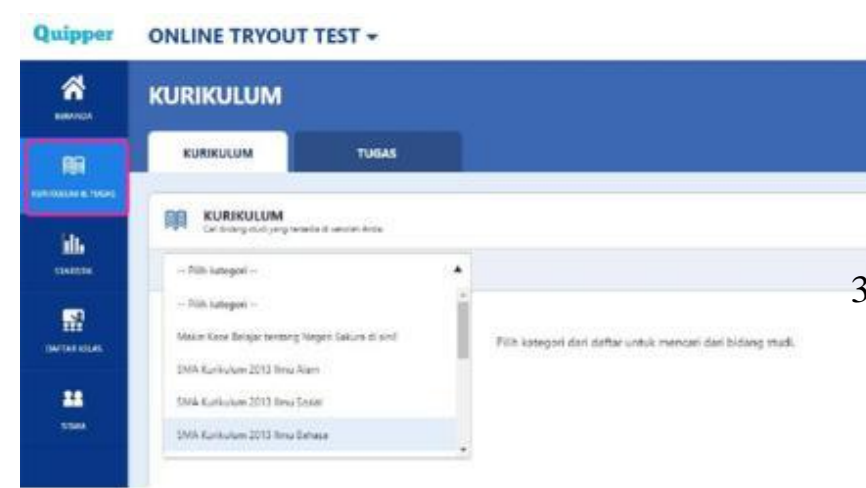

Gambar 9. Mengirimkan Tugas ke Akun

$$
\text { QLearn }
$$

3. Memantau Proses belajar siswa

Quipper menyediakan laporan proses pengerjaan tugas dan juga laporan nilai siswa untuk memudahkan guru memantau proses belajar siswa.

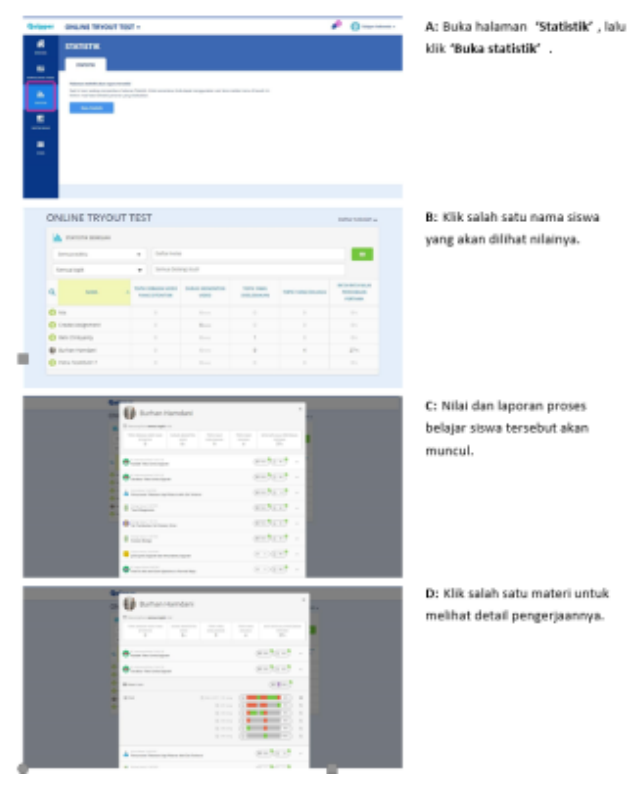

\section{PENUTUP}

Proses pengamatan tim pelaksana selama kegiatan dan hasil kegiatan dapat disimpulkan:

1. $100 \%$ peserta dapat mengikuti kegiatan pelatihan dari awal sampai dengan selesaikan kegiatan.

2. $90 \%$ peserta dapat membuat media ajar yang interaktif. Sedangkan $10 \%$ masuk dalam kategori sedang, karena ada hambatan pada saat kegiatan seperti internet ada yang down.

3. Dengan adanya kegiatan pelatihan, maka peserta dapat memotivasi guruguru lain yang ada disekolah masingmasing. 


\section{DAFTAR PUSTAKA}

Gardner, Susannah., Birley, Shane., 2008,

"Blogging For Dummies 2nd Edition”, John Wiley \& Sons, New York.

Hudoyo, Herman. 1990. Strategi Mengajar Belajar Matematika. Malang : IKIP Malang

Pujadi, T. 2008. Blog Dan Rss Sebagai Sarana Kolaborasi Untuk Meningkatkan Pemerataan Akses Belajar. Makalah disampaikan pada International Conference ICT Education UNY Yogyakarta

Sudjana, Nana \& Rivai, Ahmad. 2002. Media Pengajaran. Bandung : Sinar Baru Algensindo

Sadiman, Arif S, et. Al. 2002. Media Pemdidikan:

Pengertian, Pengembangan dan Pemanfaatannya. Jakarta : Raja Grafindo Persada 